\title{
Simple detection of genomic microdeletions and microduplications using QMPSF in patients with idiopathic mental retardation
}

\author{
Pascale Saugier-Veber* ${ }^{*}, 2$, Alice Goldenberg ${ }^{1}$, Valérie Drouin-Garraud ${ }^{1}$,
} Céline de La Rochebrochard ${ }^{3}$, Valérie Layet ${ }^{4}$, Nathalie Drouot ${ }^{1,2}$, Nathalie Le Meur ${ }^{5}$, Brigitte Gilbert-Du-ssardier ${ }^{6}$, Géraldine Joly-Hélas ${ }^{3}$, Hélène Moirot ${ }^{3}$, Annick Rossi ${ }^{5}$, Mario Tosi $^{2}$ and Thierry Frébourg ${ }^{1,2}$

\footnotetext{
${ }^{1}$ Department of Genetics, Rouen University Hospital, Rouen, France; ${ }^{2}$ Inserm U614, Faculty of Medicine, 22 boulevard Gambetta, Rouen, France; ${ }^{3}$ Department of Cytogenetics, Rouen University Hospital, Rouen, France; ${ }^{4}$ Department of Cytogenetics, Le Havre Hospital, Le Havre, France; ${ }^{5}$ Department of Genetics, Etablissement Français du Sang, BoisGuillaume, France; ${ }^{6}$ Department of Genetics, Jean Bernard University Hospital, Poitiers, France
}

In contrast to the numerous well-known microdeletion syndromes, only a few microduplications have been described, and this discrepancy may be due in part to methodological bias. In order to facilitate the detection of genomic microdeletions and microduplications, we developed a new assay based on QMPSF (Quantitative Multiplex PCR of Short fluorescent Fragments) able to explore simultaneously 12 candidate loci involved in mental retardation (MR) and known to be the target of genomic rearrangements. We first screened 153 patients with MR and facial dysmorphism associated with malformations, or growth anomalies, or familial history, with cytogenetically normal chromosomes, and the absence of FRAXA mutation and subtelomeric rearrangements. In this series, we found a $5 q 35$ deletion removing the NSD1 gene in a patient with severe epilepsy, profound MR and, retrospectively, craniofacial features of Sotos syndrome. In a second series, we screened 140 patients with MR and behaviour disturbance who did not fulfil the de Vries criteria for subtelomeric rearrangements and who had a normal karyotype and no detectable FRAXA mutation. We detected a 22q11 deletion in a patient with moderate MR, obesity, and facial dysmorphism and a $4 \mathrm{Mb} 17 \mathrm{p} 11$ duplication in a patient with moderate MR, behaviour disturbance, strabismus, and aspecific facial features. This new QMPSF assay can be gradually upgraded to include additional loci involved in newly recognised microduplication/microdeletion syndromes, and should facilitate wide screenings of patients with idiopathic MR and provide better estimates of the microduplication frequency in the MR population.

European Journal of Human Genetics (2006) 14, 1009-1017. doi:10.1038/sj.ejhg.5201661; published online 14 June 2006

Keywords: QMPSF; microdeletion; microduplication

Introduction

Mental retardation (MR) occurs in $2-3 \%$ of the general population, but its aetiology can be established only in

*Correspondence: Dr P Saugier-Veber, Inserm U614, Faculty of Medicine, 22 boulevard Gambetta, 76183 Rouen, France.

Tel: + 332328888 58; Fax: + 33232888080 ;

E-mail: Pascale.Saugier-Veber@chu-rouen.fr

Received 1 December 2005; revised 6 April 2006; accepted 13 April 2006; published online 14 June 2006 approximately $50 \%$ of cases, limiting therefore considerably the efficiency of genetic counselling, detection of carriers, and prenatal diagnosis. ${ }^{1}$ In this context, the detection and characterisation of deleterious genomic rearrangements, such as microdeletions and microduplications, represents an important challenge. These rearrangements, resulting mainly from abnormal pairing and nonallelic homologous recombination mediated by repeat elements such as Alu repeats and low-copy repeats (LCRs), 
are the cause of many Mendelian diseases, contiguous gene syndromes, or chromosomal disorders. ${ }^{2-4}$ Other uncharacterised recombinational hotspots may also key roles, especially in subtelomeric regions where chromosomal rearrangements are found in about $5 \%$ of the patients with idiopathic MR. ${ }^{5-7}$ Thus, genome architectural features are involved in the origin of recurrent deleterious DNA rearrangements. ${ }^{3,8,9}$ The use of FISH has significantly improved the diagnosis of microdeletion syndromes suggested by clinical evidence. Nevertheless, recent descriptions of microduplication syndromes in patients with MR have highlighted the wide phenotypic variability complicating their clinical recognition. Although nonallelic homologous recombination is supposed to generate microdeletions as well as microduplications, in the field of MR only four microduplications have clearly been related to phenotypes: a 15q11-q13 duplication has been detected in patients presenting autistic features and its frequency has been estimated to 1/200-600 among patients with developmental delay. ${ }^{10,11}$ A 17 p11.2 duplication has been associated with moderate $\mathrm{MR}$ and behavioural disturbance. ${ }^{12,13}$ The 22q11 duplication, initially identified in patients with a clinical presentation similar to the classical 22q11 deletion, has recently been shown to result into a highly variable phenotype. ${ }^{14,15}$ A $7 q 11.23$ duplication has been related to severe expressive language delay. ${ }^{16}$ Among the possible explanations for the lower frequency of observed duplications, compared to deletions, one can speculate that duplications often result in a different or less severe phenotype and/or that a methodological bias contributes to this discrepancy. Therefore, systematic molecular screenings of patients ascertained independently of the clinical presentation should facilitate the characterisation of the clinical spectrum of microduplications.

CGH-array at a $1 \mathrm{Mb}$ resolution will probably represent in a near future the most attractive tool for genomewide screening to investigate patients with idiopathic MR. Nevertheless, the recent findings highlighting the previously unsuspected extend of the copy-number polymorphisms in the human genome ${ }^{17-19}$ hampers, at the present time, its use on a routine basis in molecular genetics laboratories. ${ }^{20-24}$ Therefore, we considered that molecular assays focused on regions that have already been identified as targets for microdeletions and microduplications should be more effective in detecting selectively deleterious rearrangements.

In order to facilitate the detection of microrearrangements and especially duplications in MR patients, we developed a simple assay based on QMPSF (Quantitative Multiplex PCR of Short Fluorescent Fragments), a method in which short genomic sequences are simultaneously amplified under quantitative conditions using dye-labelled primers. QMPSF has been shown to be a sensitive method for the detection of both deletions and duplications ${ }^{25-28}$ and is currently used in numerous molecular diagnostic laboratories. The QMPSF assay that we developed for the present study explores simultaneously 12 candidate loci known to be the target of genomic rearrangements and involved in MR. Here, we report the results obtained on two series of patients with idiopathic MR, the first series consisting of 153 patients referred for subtelomeric rearrangement screening, and the second series consisting of 140 patients referred for fragile X syndrome testing.

\section{Patients and methods \\ Patients}

A total of 293 patients was analysed in this study. For each patient, blood samples were collected after having obtained written informed consent. Each patient had been examined by a clinical geneticist or a experienced pediatrician and had been diagnosed with developmental delay. The study population was divided into two groups: the first series was composed of 153 patients (92 males and 61 females) with MR and facial dysmorphism associated with malformations, or growth anomalies, or familial history. The additional inclusion criteria were cytogenetically normal chromosomes and no detectable subtelomeric rearrangement. In this series, 69 cases $(45.5 \%)$ presented with a familial history of MR, whereas 83 cases (54\%) were sporadic and the familial history of one patient was unknown because of adoption. The second series was composed of 140 consecutive files of patients (104 males and 36 females) with MR and behaviour disturbance referred for Fragile $\mathrm{X}$ syndrome testing. These patients did not fulfil the de Vries criteria for subtelomeric rearrangements, exhibited normal chromosomes and did not harbour expansions within the FMR1 gene. ${ }^{29}$ In this second series, 35 cases (25\%) presented with a familial history of MR, whereas 104 cases (74\%) were sporadic and one patient was adopted. Genomic DNA was extracted from peripheral blood lymphocytes using the QIAamp DNA blood mini kit (Qiagen, Courtaboeuf, France).

\section{QMPSF analyses}

Short exonic fragments $(170-240 \mathrm{pb})$ of 12 candidate loci (Table 1) were simultaneously PCR amplified, in a single tube, using dye-labelled primers corresponding to unique sequences (Table 2). An additional fragment, corresponding to exon 13 of the $H M B S$ gene located on chromosome 11 , was coamplified, as a control. PCR was performed in a final volume of $25 \mu \mathrm{l}$ containing $100 \mathrm{ng}$ of genomic DNA, $0.3-0.9 \mu \mathrm{M}$ of each primer, $200 \mu \mathrm{M}$ dNTPs, $1.5 \mathrm{mM} \mathrm{MgCl}_{2}$, $10 \%$ of DMSO, and $1 \mathrm{U}$ of Taq DNA polymerase (ABgene, Courtaboeuf, France). The PCR consisted of 22 cycles of $94^{\circ} \mathrm{C}$ for $10 \mathrm{~s}, 52^{\circ} \mathrm{C}$ for $15 \mathrm{~s}$, and $72^{\circ} \mathrm{C}$ for $20 \mathrm{~s}$, preceded by an initial denaturation step of $5 \mathrm{~min}$ at $94^{\circ} \mathrm{C}$ and followed by a final extension of $5 \mathrm{~min}$ at $72^{\circ} \mathrm{C}$. One $\mu \mathrm{l}$ of the PCR product was resuspended in a mix containing $1.25 \mu \mathrm{l}$ of 
Table 1 Genes selected for the microdeletion/microduplication QMPSF assay

\begin{tabular}{llclr}
\hline Type of genetic disorder & Gene & Localisation & Syndrome & MIM \\
\hline LCR-mediated disorder & NSD1 & $5 \mathrm{q} 35$ & Sotos & 117550 \\
& ELN & $7 \mathrm{q} 11.23$ & Williams-Beuren & 194050 \\
& SNRPN & $15 \mathrm{q} 11$ & Prader-Willi/Angelman & $176270 / 105830$ \\
& LOXL1 & $15 \mathrm{q} 24$ & Panic and phobic disorder & 182290 \\
& RAI1 & $17 \mathrm{p} 11.2$ & Smith-Magenis & 188400 \\
Subtelomeric syndrome & TBX1 & $22 \mathrm{q} 11.2$ & DiGeorge/Velocardiofacial & 194190 \\
& WHSC1 & $4 \mathrm{p} 16.3$ & Wolf-Hirschhorn & 123450 \\
Contiguous gene syndrome $^{\mathrm{b}}$ & SEMA5A & $5 \mathrm{p} 15.2$ & Cri-du-chat & 247200 \\
& LIS1 & $17 \mathrm{p} 13.3$ & Miller-Dieker & 150230 \\
Mendelian disease $^{\mathrm{b}}$ & EXT1 & $8 \mathrm{q} 24.1$ & Langer-Giedion & 194072 \\
\hline
\end{tabular}

${ }^{a}$ Gratacos et al (2001).

${ }^{\mathrm{b}}$ Of unknown mechanism.

'Wilms tumour - Aniridia - Genitourinary anomalies - mental Retardation syndrome.

Table 2 Primers used for the microdeletion/microduplication QMPSF assay

\begin{tabular}{|c|c|c|c|}
\hline Targeted gene & Localisation & Primers & Size of the amplicon (bp) \\
\hline WT1 & $11 \mathrm{p} 13$ & 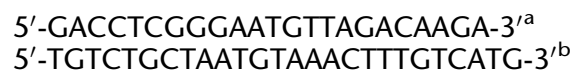 & 131 \\
\hline$E L N$ & $7 q 11.23$ & $\begin{array}{l}5^{\prime}-\text { GTTGGTGTCGGCGTCCC- } 3^{\prime a} \\
5^{\prime}-\text { TCAGGGGACAGGCTCCG-3 }\end{array}$ & 142 \\
\hline WHSC1 & $4 p 16.3$ & $\begin{array}{l}5^{\prime} \text {-GGGCCTATCTTCTGAACTCGCT- } 3^{\prime a} \\
5^{\prime} \text {-ACTTCAGTCGGTGGTGATTTGT-3 } 3^{\prime b}\end{array}$ & 171 \\
\hline EXT1 & $8 q 24.1$ & $\begin{array}{l}5^{\prime}-\text {-CCTTCCTTACCTCTAATAACAATC- } 3^{\prime a} \\
5^{\prime}-\text {-CTCTCGCTTCCTCACATTCAC- } 3^{\prime b}\end{array}$ & 182 \\
\hline CREBBP & $16 p 13.3$ & $\begin{array}{l}5^{\prime}-\text { TCACCTGGTTGGGTCGGG-3/a } \\
5^{\prime}-\text {-CTCCTGCAGCGGTGGAA-3 } 3^{\prime b}\end{array}$ & 192 \\
\hline LIS1 & $17 p 13.3$ & $\begin{array}{l}5^{\prime} \text {-AAGATAAAATTCTGAACTGCGTTTT- } 3^{\prime a} \\
5^{\prime} \text {-CAAGCTAGACATAAAGCTGCTTCTA- } 3^{\prime b}\end{array}$ & 200 \\
\hline$R A / 1$ & $17 p 11.2$ & $\begin{array}{l}5^{\prime}-\text { GGCTATGCTCAGTTAGGGGTT- } 3^{\prime a} \\
5^{\prime}-\text { GAGTAGGCGCGGCGGT- } 3^{\prime b}\end{array}$ & 226 \\
\hline LOXL1 & $15 q 24$ & $\begin{array}{l}\text { 5'-CGCCCTTCGTCAGCCA-3'a } \\
5^{\prime}-\text {-GCCGGGTAGAAGCCCTG-3/ }\end{array}$ & 237 \\
\hline NSD1 & $5 q 35$ & 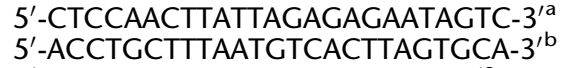 & 253 \\
\hline TBX1 & $22 q 11.2$ & $\begin{array}{l}\text { 5'-GCGGTTCAGACACTGGACATT-3/a } \\
\text { 5'-GGGTATTGAAGGGTTGGCACT-3 } 3^{\prime b}\end{array}$ & 267 \\
\hline SNRPN & $15 q 11$ & $\begin{array}{l}\text { 5'-GGTTGGTGCTGAGGACAAAAGAG-3/a } \\
5^{\prime} \text {-ACTGCTACCACCTCTGAAGTCCC-3/b }\end{array}$ & 280 \\
\hline SEMA5A & $5 p 15.2$ & $\begin{array}{l}5^{\prime}-\text { TGAAGGAGTTTCCAAGACAGGT- }{ }^{\prime \prime a} \\
5^{\prime}-\text { ATCCCATTTTCTTCGTACCA-3 } 3^{\prime b}\end{array}$ & 290 \\
\hline$H M B S^{C}$ & $11 q 23$ & $\begin{array}{l}5^{\prime} \text { ACGGCTCAGATAGCATACAAG } 3^{\prime a} \\
5^{\prime} \text { ATGCCTACCAACTGTGGGTCA } 3^{\prime b}\end{array}$ & 208 \\
\hline
\end{tabular}

\footnotetext{
${ }^{a}$ Sense primer. An universal extension ( $5^{\prime}$-CGTTAGATAG- $\left.3^{\prime}\right)$ was added to the $5^{\prime}$ end of this primer.

${ }^{\mathrm{b}}$ Antisense primer. An universal extension ( $5^{\prime}$-GATAGGGTTA- $3^{\prime}$ ) was added to the $5^{\prime}$ end of this primer.

${ }^{\mathrm{C}}$ Reference amplicon.
}

deionised formamide, $0.5 \mu \mathrm{l}$ of GeneScan-500 Rox (PE Applied Biosystems, Foster City, CA, USA), and $1 \mu \mathrm{l}$ of loading buffer. After denaturation for $3 \mathrm{~min}$ at $90^{\circ} \mathrm{C}, 2 \mu \mathrm{l}$ of each sample was loaded on an Applied Biosystems model 3100 automated sequencer (PE Applied Biosystems, Foster City, CA, USA). The data were analysed using the Genescan software (PE Applied Biosystems, Foster City, CA, USA). Electropherograms were superimposed to those generated from a normal control DNA by adjusting to the same level the peaks obtained for the control amplicon and the heights of the corresponding peaks were then compared between the different samples.

Abnormal profiles were confirmed with a locus-specific QMPSF. The Sotos QMPSF includes amplicons exploring the 22 coding exons of the NSD1 gene. The DiGeorge QMPSF includes 22 amplicons corresponding to 22 genes 
localised within the $22 \mathrm{q} 11$ region $^{30}$ and two amplicons within the 10 p14 region. The Smith-Magenis QMPSF includes 13 amplicons specific of 12 genes within the 17 p11.2 region (the corresponding primer sequences are available upon request).

\section{FISH}

FISH validation experiments were performed on both interphase and metaphase cells using routine procedures. To validate the $17 \mathrm{p} 11.2$ duplication, we used a probe specific of the Smith-Magenis Syndrome critical region (Vysis, Downers Groove, USA), which encompasses the SHMT1, TOP3, FLII, LLGL1 genes. To validate the 22q11 deletion, a probe specific of the DiGeorge critical region (Vysis, Downers Groove, USA) encompassing the TUPLE1/ HIRA gene and the D22S553, D22S609, D22S942 loci was used.

\section{Results}

We developed a molecular assay, based on the QMPSF method, which is suitable for rapid screening of large series of DNA samples for common microdeletion and microduplication syndromes. This new QMPSF assay includes 12 exonic amplicons, each corresponding to a distinct locus involved in MR (Table 1). Six amplicons correspond to genes of interest located within the deleted interval of six genomic disorders, that is: Sotos syndrome (MIM 117550, NSD1 gene), Williams-Beuren syndrome (MIM 194050, ELN gene), Prader-Willi and Angelman syndromes (MIM 176270 and MIM 105830, respectively, SNRPN gene), panic and phobic disorder (LOXL1 gene), ${ }^{31}$ Smith-Magenis syndrome (SMS, MIM 182290, RAI1 gene) and DiGeorge syndrome/velocardiofacial syndrome (MIM 188400, TBX1 gene). Three other amplicons explore 3 subtelomeric regions involved in Wolf-Hirschhorn (MIM 194190, WHSC1 gene), cri-du-chat (MIM 123450, SEMA5A gene) and Miller-Dieker (MIM 247200, LIS1 gene) syndromes, respectively. We also selected two amplicons exploring the interval deleted in two contiguous gene syndromes whose molecular mechanism is unknown: Langer-Giedion syndrome (MIM 150230, EXT1 gene) and WAGR (MIM 194072, WT1 gene). Finally, we included an amplicon corresponding to the CREBBP1 gene involved in Rubinstein-Taybi syndrome, a syndromic MR frequently resulting from microdeletions (MIM 180849). In this new QMPSF assay, short exonic fragments (170-240 pb) of these 12 candidate loci are PCR amplified simultaneously, in a single tube, using dye-labelled primers corresponding to unique sequences (Table 2). Moreover, we have previously designed several locus-specific QMPSF assays, described in Patients and methods that can be used for more detailed analysis of most of the regions included in this new QMPSF assay.

We first validated this QMPSF assay by using positive controls consisting of DNA samples from patients presenting with either Williams-Beuren, Smith-Magenis, Sotos, DiGeorge, 22q11 duplication, Prader-Willi, or cri-du-chat syndromes and harbouring, in each case, a heterozygous deletion or duplication of the corresponding gene. As shown in Table 3, in QMPSF analysis, heterozygous deletions can easily be detected by a 0.5 reduction of the peak heights whereas duplications result in a 1.5 increase.

We then screened 293 patients with MR. In the first series, we analysed 153 patients referred for subtelomeric testing, presenting with clinical criteria suggestive of the

Table 3 Validation of the microdeletion/microduplication QMPSF assay using positive controls consisting of DNA samples from patients presenting with either Williams-Beuren (WBS), Smith-Magenis (SMS), Sotos, DiGeorge (DGS), 22q11 duplication (22dup), Prader-Willi (PWS), or cri-du-chat syndromes. Bold values correspond to the detection of either a microdeletion or a microduplication using the amplicon within the gene of interest for each positive control

\begin{tabular}{|c|c|c|c|c|c|c|c|}
\hline Targeted gene & $\begin{array}{l}\text { Patient with } \\
\qquad W B S^{\mathrm{a}}\end{array}$ & $\begin{array}{l}\text { Patient with } \\
\text { SMS }^{\mathrm{a}}\end{array}$ & $\begin{array}{l}\text { Patient with } \\
\text { Sotos }^{\mathrm{a}}\end{array}$ & $\begin{array}{l}\text { Patient with } \\
D G S^{\mathrm{a}}\end{array}$ & $\begin{array}{c}\text { Patient with } \\
22 d u p^{\mathrm{a}}\end{array}$ & $\begin{array}{c}\text { Patient with } \\
\text { PWS }^{\mathrm{a}}\end{array}$ & $\begin{array}{l}\text { Patient with } \\
\text { cri-du-chat }^{\mathrm{a}}\end{array}$ \\
\hline WT1 & 1.047 & 1.069 & 0.993 & 1.023 & 1.023 & 1.033 & 0.998 \\
\hline ELN & 0.521 & 1.026 & 0.932 & 0.943 & 1.169 & 1.004 & 0.996 \\
\hline WHSC1 & 1.078 & 0.974 & 1.083 & 0.968 & 1.025 & 1.002 & 1.032 \\
\hline EXT1 & 1.024 & 0.994 & 0.977 & 1.015 & 1.052 & 1.020 & 0.981 \\
\hline CREBBP & 1.247 & 1.046 & 0.930 & 1.059 & 1.013 & 1.033 & 1.082 \\
\hline LIS1 & 1.064 & 0.995 & 1.009 & 1.028 & 1.032 & 1.023 & 0.928 \\
\hline$H M B S^{b}$ & 1.000 & 1.000 & 1.000 & 1.000 & 1.000 & 1.000 & 1.000 \\
\hline$R A / 1$ & 0.976 & 0.487 & 0.946 & 0.965 & 1.045 & 0.957 & 0.991 \\
\hline LOXL1 & 1.028 & 0.962 & 1.017 & 0.950 & 1.050 & 0.978 & 0.964 \\
\hline NSD1 & 0.999 & 0.973 & 0.528 & 1.043 & 0.998 & 1.019 & 0.999 \\
\hline TBX1 & 1.062 & 0.960 & 0.928 & 0.466 & 1.503 & 0.962 & 0.970 \\
\hline SNRPN & 1.142 & 0.999 & 1.078 & 1.017 & 0.975 & 0.534 & 1.055 \\
\hline SEMASA & 1.199 & 1.018 & 1.112 & 1.002 & 1.019 & 1.032 & 0.486 \\
\hline
\end{tabular}

The copy-number change for each locus has been calculated using the peak height $H$ of each locus-specific peak (see Figures $1 \mathrm{a}$, 2a and $3 \mathrm{a}$ ) normalised to the peak heights $H_{H M B S}$ of the $H M B S$ control ( $\mathrm{C}$ in Figures $1 \mathrm{a}, 2 \mathrm{a}$ and $\left.3 \mathrm{a}\right)$. The following formula was used: $\left(H_{\text {patient }} / H_{\text {control }}\right) \times\left(H_{H M B S}\right.$

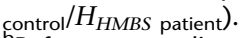

Reference amplicon.
b 
presence of a chromosomal abnormality, without detectable subtelomeric rearrangements. The QMPSF profiles revealed, in one patient, a 50\% reduction of the peak corresponding to the NSD1 amplicon (Figure 1a). Subsequent QMPSF analysis, specific of the NSD1 locus, confirmed the existence of a 5q35 heterozygous deletion removing all the coding exons of the NSD1 gene (Figure 1b) and suggested the diagnosis of Sotos syndrome in this patient, who presented with profound MR in the context of generalised seizures. He was the first child of unrelated parents, born at term after an uneventful pregnancy with normal mensurations and developed West syndrome at 3 months of age. At 12 years of age, he presented with profound MR (he could not walk and talk), macrocephaly with head circumference above the 98th centile, normal height, a long and narrow face with pointed chin. Cerebral resonance magnetic imaging showed slight dilatation of cerebral ventricules.

In the second series, we screened 140 patients with MR and behaviour disturbance referred for Fragile $\mathrm{X}$ syndrome testing. In one patient, the QMPSF profile revealed a heterozygous deletion of the TBX1 amplicon exploring the $22 \mathrm{q} 11$ region (Figure 2a). A 22q11 locus QMPSF analysis ${ }^{30}$ showed that this patient harbour the classical $3 \mathrm{Mb} 22 \mathrm{q} 11$ deletion associated with DiGeorge syndrome (Figures $2 b$ and c), and this rearrangement was confirmed by FISH (Figure 2c). These results led to the diagnosis of a $22 \mathrm{q} 11$ deletion syndrome in this 25-year-old man who presented with moderate developmental delay, seizures, overweight stature, and facial dysmorphism including a bulbous nose and short palpebral fissures. He spoke correctly but his voice sounded mildly nasal. His IQ was estimated at 46 and he presented behaviour disturbance such as tantrums. Cardiac and renal ultrasonographies revealed no malformation.

In the same series, the QMPSF assay revealed a 1.5 increase of the peak corresponding to the RAI1 amplicon (Figure 3a). Subsequent QMPSF analyses in this patient, using a QMPSF specific of the 17p11 locus, confirmed the 17 p11 duplication and allowed us to estimate to $4 \mathrm{Mb}$ the size of the duplicated segment (Figures $3 \mathrm{~b}$ and c). This rearrangement was confirmed by FISH (Figure 3c). We
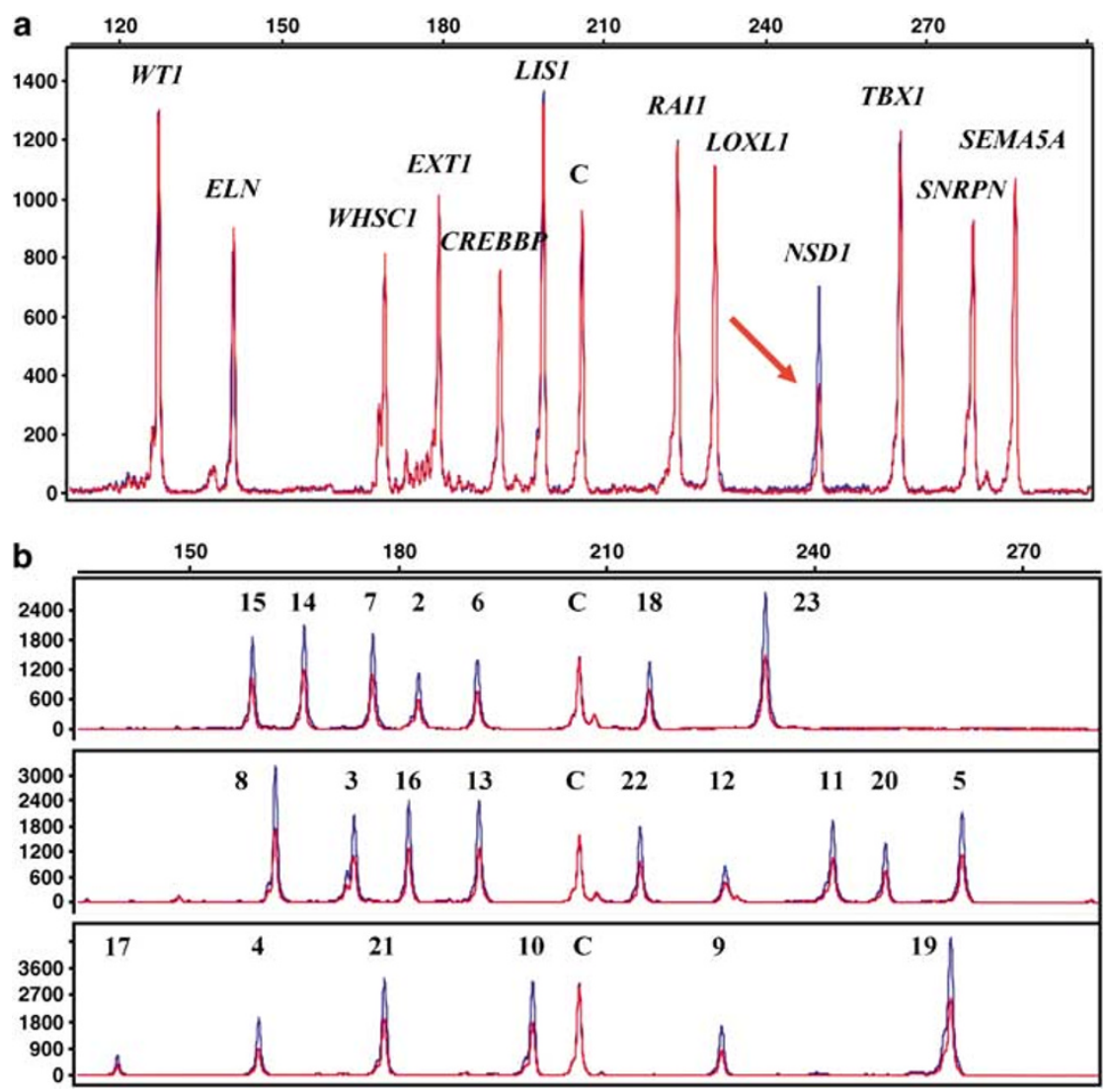

Figure 1 Detection by QMPSF assays of a $5 q 35$ deletion removing the NSD1 locus. (a) Detection of the heterozygous NSD1 deletion using the microdeletion/microduplication QMPSF assay. (b) Confirmation of the rearrangement using a QMPSF assay exploring the 22 coding exons of the NSD1 gene. In each QMPSF panel, the electropherogram of the patient (in red) was superimposed to that of a normal control (in blue) by adjusting to the same level the peaks obtained for the control amplicon. The $Y$ axis displays fluorescence in arbitrary units, and the $X$ axis indicates the size in bp. Heterozygous deletions are easily detected by a $50 \%$ reduction of the peaks compared to a normal control. In panel (a), each amplicon corresponds to a single locus. In panel (b), the numbers correspond to the NSD1 exons. In both, C designs the control amplicon. 


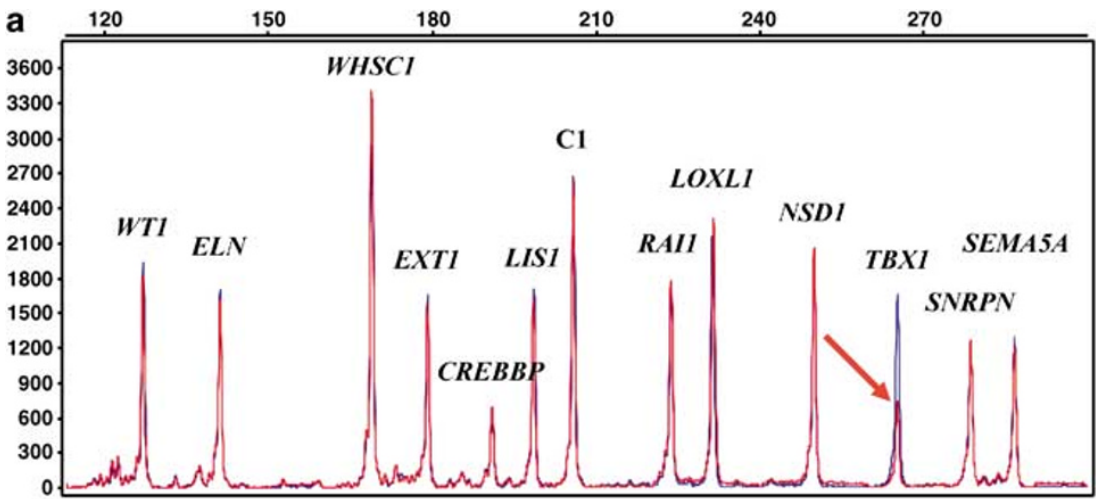

C cen
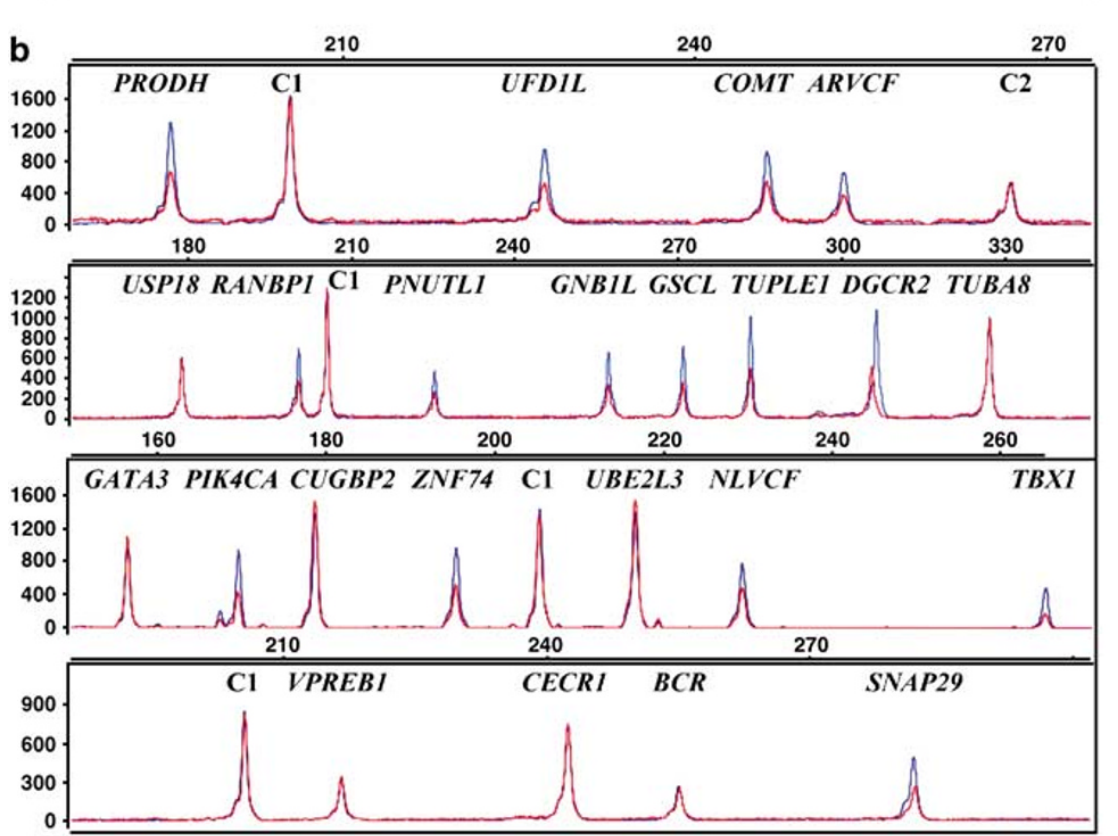

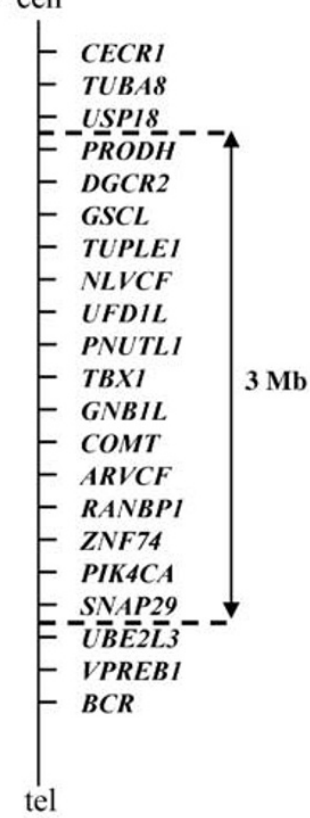

d

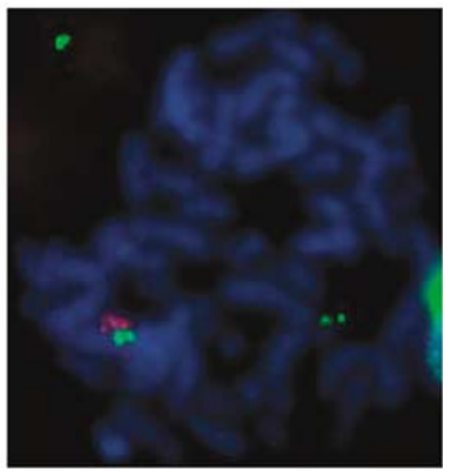

Figure 2 Detection by QMPSF assays of a 22q11.2 deletion. (a) Detection of the 22q11.2 deletion using the microdeletion/microduplication QMPSF assay. (b) Characterisation of the boundaries of the rearrangement using a QMPSF specific of the 22q11.2 and 10p14 loci. In each QMPSF panel, the electropherogram of the patient (in red) was superimposed to that of a normal control (in blue) by adjusting to the same level the peaks obtained for the control amplicon. The $Y$ axis displays fluorescence in arbitrary units, and the $X$ axis indicates the size in bp. In both (a) and (b), C1 and C2 design control amplicons. (c) Schematic representation of the position of the $22 q 11$ amplicons along the chromosome $22 .{ }^{30}$ The arrow shows the extend of the deletion revealed by QMPSF. (d) Confirmation by FISH of the rearrangement using the Spectrum Orange LSI DiGeorge/VCSF region probe (Vysis, Downers Groove, USA) which encompasses the TUPLE1/HIRA gene and the D22S553, D22S609, D22S942 loci and the Spectrum Green LSI ARSA control probe on 22q13 (Vysis, Downers Groove, USA).

identified this $17 \mathrm{p} 11$ duplication in a 5 -year-old boy presenting with MR, mild facial dysmorphic features and behaviour disturbance. He was born after an uneventful pregnancy. Caesarean section was performed at full term for nonprogression of the labour. Clinical examination and mensurations at birth were normal. He was the first child of young and nonconsanguineous parents. Family history was unremarkable. As an infant, he was described as very calm and not interested by social activities. He was able to sit after the age of 1 year and could walk unaided at 18 months of age. First words appeared after the age of 3 years. Between 3 and 4 years, moderate behaviour disturbance (attention deficit, agitation, frustration intolerance) was noted. No sleep disturbance was noticed. At the age of 5 years and 8 months, he presented with normal physical examination, normal growth, and normal neurological examination. Social interaction was good, but language was severely impaired. Mild facial dysmorphic features included high and wide forehead, moderate hypertelorism, thin upper lip, short philtrum and divergent strabismus (Figure 3e). Cerebral RMN was normal. IQ evaluation was impossible because of behavioural disturbance. In order to provide genetic counselling within this family, parents were tested by QMPSF and FISH since the latter method is 


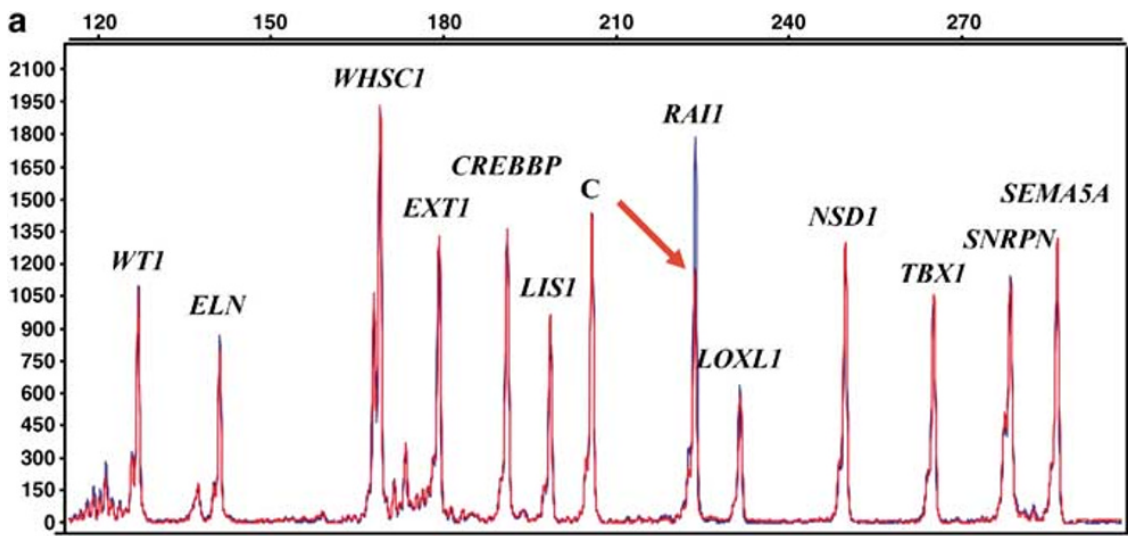

C cen
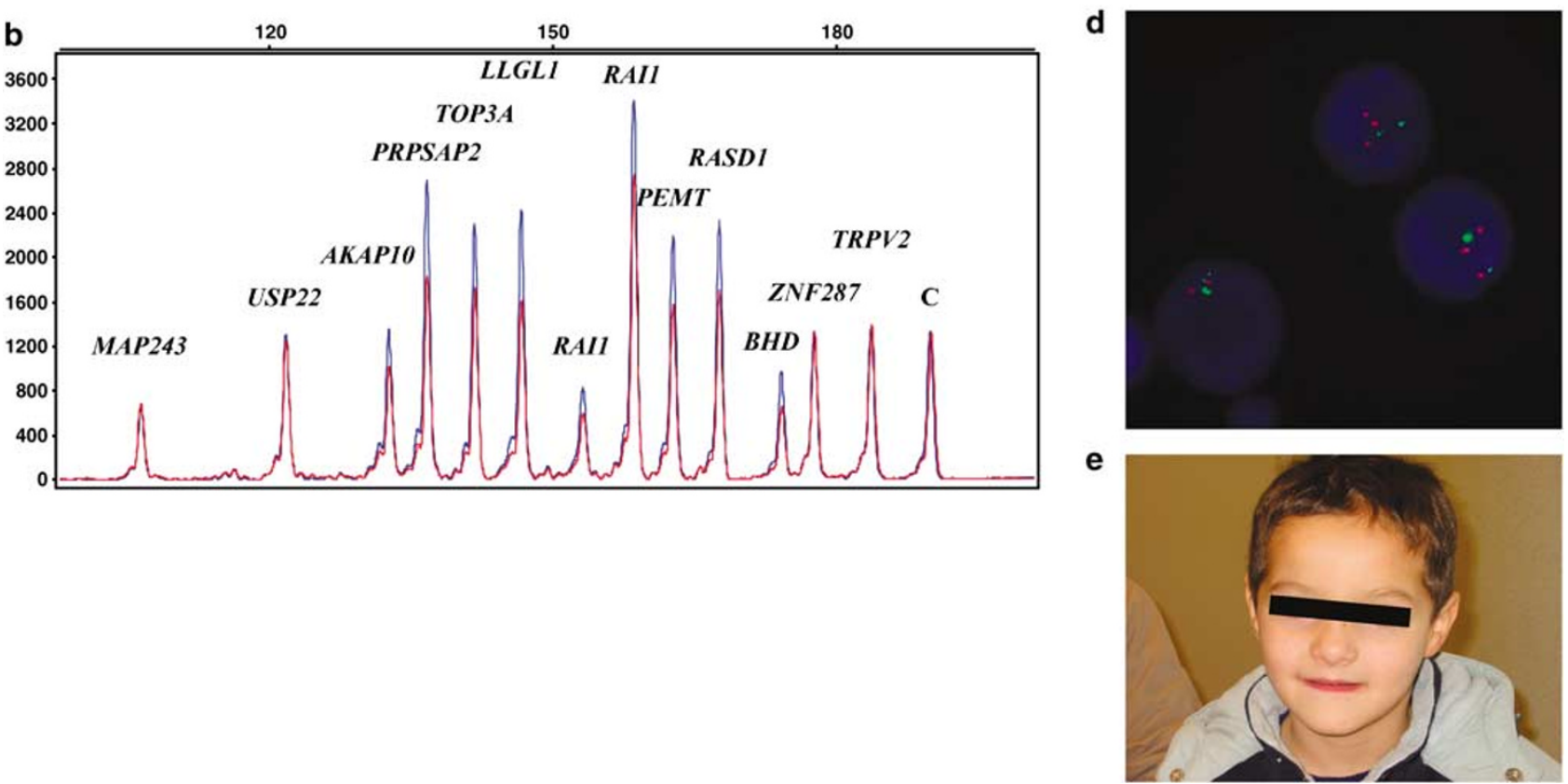

Figure 3 Detection by QMPSF assays of a 17p11.2 duplication syndrome. (a) Detection of the 17p11.2 duplication using the microdeletion/ microduplication QMPSF assay. (b) Characterisation of the boundaries of the rearrangement using a QMPSF specific of the $17 \mathrm{p} 11.2$ locus. In each QMPSF panel, the electropherogram of the patient (in blue) was superimposed to that of a normal control (in red) by adjusting to the same level the peaks obtained for the control amplicon. The $Y$ axis displays fluorescence in arbitrary units, and the $X$ axis indicates the size in bp. In both (a) and (b), $C$ designs the control amplicon. (c) Schematic representation of the position of the 17p11 amplicons along the chromosome 17. The arrow shows the extend of the deletion revealed by QMPSF. (d) Confirmation by FISH of the rearrangement using the Spectrum Orange LSI Smith-Magenis Syndrome critical region probe (Vysis, Downers Groove, USA) and the Spectrum Green LSI Retinoic Acid Receptor Alpha (LSI RARA) control probe on 17q21.1 (Vysis, Downers Groove, USA). (e) Phenotype of the patient with the 17p11.2 duplication.

the only one which can detect balanced rearrangements, whereas QMPSF had a higher sensitivity than FISH to detect duplications. These analyses show that the parents did not harbour the 17 p11 duplication or a balanced translocation, suggesting a de novo occurrence.

\section{Discussion}

In order to facilitate systematic molecular screenings of MR patients for microrearrangements, we developed a new assay based on the QMPSF method and focused on 12 genomic regions involved in MR and corresponding to Alu/ LCRs-mediated rearrangements or subtelomeric imbalances (Table 1). Using this microdeletion/microduplication QMPSF, we screened 293 patients with developmental delay and we identified three genomic rearrangements: a NSD1 deletion leading subsequently to the diagnosis of Sotos syndrome, a 22q11 deletion and a $17 \mathrm{p} 11$ duplication (Figures 1, 2 and 3). It is noteworthy that, like in our case, the eight $17 \mathrm{p} 11$ duplications reported so far have been identified in the course of wide chromosomal screenings of MR patients. ${ }^{12,32}$ The clinical features of these eight 
patients with 17 p11 duplication include mild to borderline MR, behavioural disturbance, short stature, and dental abnormalities, and no specific phenotype could be identified, underlying the importance of wide screenings.

In most laboratories, microdeletions and microduplications are usually detected using FISH. Ensenauer et al ${ }^{14}$ have screened 653 patients referred for DG/VCFS syndrome testing by FISH, using the TUPLE1 probe on interphase cells, and found a 22q11 microduplication in 13 patients (2\%). Similarly, Lese-Martin et $a^{33}$ have analysed, by FISH using a SNRPN probe, 148 patients with autism spectrum disorders and found that two patients (1.4\%) harbour a 15q11-q13 microduplication. Finally, Keller et $a l^{34}$ have screened 49 autistic children by FISH, using the D15S10 (15q11.2) and FLII (17p11.2) DNA probes, and detected a single case of 15q11-q13 microduplication (2\%) but no 17p11.2 microduplication. ${ }^{34}$ Thus, FISH can be efficiently used to screen for a specific rearrangement but is not suitable for high throughput diagnostic screening of MR patients. Several new technologies have been developed to facilitate large-scale and genomewide screening of microdeletions and microduplications. A MAPH (multiple amplifiable probe hybridisation)-based assay, investigating simultaneously 162 loci corresponding to subtelomeric regions or interstitial genomic segments, allowed Kriek et $a l^{32}$ to detect 15 genomic imbalances including seven duplications among 188 patients with MR (8\%). Several studies, based on $\mathrm{CGH}$-array at a $1 \mathrm{Mb}$ resolution, reported, in about $25 \%$ of MR patients, the presence of genomic imbalances, $30-42 \%$ of which corresponding to duplications. $^{20-22}$ While CGH-array seems to be the most attractive tool for genomewide screening, its use for guiding genetic counselling is limited by the fact that one cannot differentiate genomic imbalances which cause abnormal phenotypes from variants unrelated to clinical alterations since recent publications have demonstrated the high degree of copy-number polymorphism in the human genome. ${ }^{17-19}$ Recently, targeted array-based GCH was developed for medical applications but its cost limits its use in medical genetics laboratories. ${ }^{35}$ Finally, MLPA (multiplex ligation-dependent probe amplification), represents a powerful technique to detect copy-number changes, including those resulting from subtelomeric rearrangements. ${ }^{36}$ Therefore, we consider that molecular methods, such as QMPSF or MLPA, represent efficient multilocus diagnostic tools zooming in on regions that have been identified as targets for microdeletions and microduplications involved in MR. Our present experience with other applications of these methods indicates that both provide similar sensitivity of detection. MLPA is a multistep assay, in which probe hybridisation, probe ligation and PCR amplification are performed sequentially, whereas QMPSF involves only one step, that is, PCR amplification, before capillary electrophoresis. This feature of QMPSF minimises the risk of sample crosscontamination and should facilitate full automation of the assay. Conversely, a single QMPSF reaction presently contains about 15 targets, whereas MLPA allows simultaneous analysis of larger numbers of targets.

Each of the genomic imbalances that we found in this study was confirmed by an independent locus-specific QMPSF, which also allowed us to determine the boundaries of the rearrangement (Figures $1 b, 2 b$ and $3 b$ ). We estimated the size of the $17 \mathrm{p} 11$ duplication to $4 \mathrm{Mb}$ by a locus-specific QMPSF indicating that this rearrangement, like previously reported cases, ${ }^{12,37}$ can be considered as the reciprocal event of the common $4 \mathrm{Mb}$ SMS deletion. (Figure $3 \mathrm{~b}$ and $\mathrm{c}$ ). Furthermore, the FISH assay proved the tandem position of the duplicated segment (Figure 3d). The SMS deletions, as well as reciprocal duplications flanked by the proximal and distal LCRs termed SMS-REP, have been shown to result from unequal crossing-over events with no parental origin bias. ${ }^{38}$

In conclusion, the microdeletion/microduplication QMPSF assay represents a powerful tool for rapid screening for microdeletions and microduplications at several candidate loci in large series of MR patients. We think that its simplicity, reproducibility, and throughput fit the requirements of medical molecular genetics laboratories. Furthermore, the flexibility of the QMPSF method will allow the gradual integration of new candidate loci recognised as deleted or duplicated in MR. This flexibility also considerably facilitates, in each patient harbouring a rearrangement, the delineation of the boundaries. The systematic screening of patients with idiopathic MR, using this type of assay, should facilitate the estimation of microduplications frequency in the MR population and the characterisation of the microduplications related phenotype.

\section{References}

1 Matilainen R, Airaksinen E, Mononen T, Launiala K, Kaariainen R: A population-based study on the causes of mild and severe mental retardation. Acta Paediatr 1995; 84: 261-266.

2 Deininger PL, Batzer MA: Alu repeats and human disease. Mol Genet Metab 1999; 67: 183-193.

3 Ji Y, Eichler EE, Schwartz S, Nicholls RD: Structure of chromosomal duplicons and their role in mediating human genomic disorders. Genome Res 2000; 10: 597-610.

4 Bailey JA, Gu Z, Clark RA et al: Recent segmental duplications in the human genome. Science 2002; 297: 1003-1007.

5 Knight SJ, Regan R, Nicod A et al: Subtle chromosomal rearrangements in children with unexplained mental retardation. Lancet 1999; 354: 1676-1681.

6 Mefford HC, Trask BJ: The complex structure and dynamic evolution of human subtelomeres. Nat Rev Genet 2002; 3: 91-102.

7 Flint J, Knight S: The use of telomere probes to investigate submicroscopic rearrangements associated with mental retardation. Curr Opin Genet Dev 2003; 13: 310-316.

8 Lupski JR: Genomic disorders: structural features of the genome can lead to DNA rearrangements and human disease traits. Trends Genet 1998; 14: 417-422.

9 Stankiewicz P, Lupski JR: Genome architecture, rearrangements and genomic disorders. Trends Genet 2002; 18: 74-82. 
10 Moeschler JB, Mohandas TK, Hawk AB, Noll WW: Estimate of prevalence of proximal $15 \mathrm{q}$ duplication syndrome. Am J Med Genet 2002; 111: 440-442.

11 Thomas JA, Johnson J, Peterson Kraai TL et al: Genetic and clinical characterization of patients with an interstitial duplication 15q11-q13, emphasizing behavioral phenotype and response to treatment. Am J Med Genet A 2003; 119: 111-120.

12 Potocki L, Chen KS, Park SS et al: Molecular mechanism for duplication $17 \mathrm{p} 11.2$ - the homologous recombination reciprocal of the Smith-Magenis microdeletion. Nat Genet 2000; 24: 84-87.

13 Moog U, Engelen JJ, Weber BW et al: Hereditary motor and sensory neuropathy (HMSN) IA, developmental delay and autism related disorder in a boy with duplication (17)(p11.2p12). Genet Couns 2004; 15: 73-80.

14 Ensenauer RE, Adeyinka A, Flynn HC et al: Microduplication 22q11.2, an emerging syndrome: clinical, cytogenetic, and molecular analysis of thirteen patients. Am J Hum Genet 2003; 73: $1027-1040$

15 Yobb TM, Somerville MJ, Willatt L et al: Microduplication and triplication of 22q11.2: a highly variable syndrome. Am J Hum Genet 2005; 76: 865-876.

16 Somerville MJ, Mervis CB, Young EJ et al: Severe expressivelanguage related to duplication of the Williams-Beuren locus. N Engl J Med 2005; 353: 1694-1701.

17 Sharp AJ, Locke DP, McGrath SD et al: Segmental duplications and copy-number variation in the human genome. Am J Hum Genet 2005; 77: 78-88.

18 Iafrate AJ, Feuk L, Rivera MN et al: Detection of large-scale variation in the human genome. Nat Genet 2004; 36: 949-951.

19 Sebat J, Lakshmi B, Troge J et al: Large-scale copy number polymorphism in the human genome. Science 2004; 305: 525-528.

20 Rosenberg C, Knijnenburg J, Bakker E et al: Array-CGH detection of micro rearrangements in mentally retarded individuals: clinical significance of imbalances present both in affected children and normal parents. J Med Genet 2006; 43: 180-186.

21 Vissers LE, de Vries BB, Osoegawa K et al: Array-based comparative genomic hybridization for the genomewide detection of submicroscopic chromosomal abnormalities. Am J Hum Genet 2003; 73: $1261-1270$

22 Shaw-Smith C, Redon R, Rickman L et al: Microarray based comparative genomic hybridisation (array-CGH) detects submicroscopic chromosomal deletions and duplications in patients with learning disability/mental retardation and dysmorphic features. J Med Genet 2004; 41: 241-248.

23 Schoumans J, Ruivenkamp C, Holmberg E, Kyllerman M, Anderlid BM, Nordenskjold M: Detection of chromosomal imbalances in children with idiopathic mental retardation by array based comparative genomic hybridisation (array-CGH). $J$ Med Genet 2005; 42: 699-705.

24 de Vries BB, Pfundt R, Leisink M et al: Diagnostic genome profiling in mental retardation. Am J Hum Genet 2005; 77: 606-616.
25 Charbonnier F, Raux G, Wang Q et al: Detection of exon deletions and duplications of the mismatch repair genes in hereditary nonpolyposis colorectal cancer families using multiplex polymerise chain reaction of short fluorescent fragments. Cancer Res 2000; 60: 2760-2763.

26 Casilli F, Di Rocco ZC, Gad S et al: Rapid detection of novel BRCA1 rearrangements in high-risk breast-ovarian cancer families using multiplex PCR of short fluorescent fragments. Hum Mutat 2002; 20: 218-226.

27 Rovelet-Lecrux A, Hannequin D, Raux G et al: APP locus duplication causes autosomal dominant early-onset Alzheimer disease with cerebral amyloid angiopathy. Nat Genet 2006; 38: $24-26$.

28 Tournier I, Paillerets BB, Sobol H et al: Significant contribution of germline BRCA2 rearrangements in male breast cancer families. Cancer Res 2004; 64: 8143-8147.

29 de Vries BB, White SM, Knight SJ et al: Clinical studies on submicroscopic subtelomeric rearrangements: a checklist. $J$ Med Genet 2001; 38: 145-150.

30 Jacquet H, Raux G, Thibaut $\mathrm{F}$ et al: PRODH mutations and hyperprolinemia in a subset of schizophrenic patients. Hum Mol Genet 2002; 11: 2243-2249.

31 Gratacos M, Nadal M, Martin-Santos R et al: A polymorphic genomic duplication on human chromosome 15 is a susceptibility factor for panic and phobic disorders. Cell 2001; 106: $367-379$.

32 Kriek M, White SJ, Bouma MC et al: Genomic imbalances in mental retardation. J Med Genet 2004; 41: 249-255.

33 Lese-Martin C, Chung J, Ilkin Y, Geschwind DH, Ledbetter DH: Molecular cytogenetic investigations of multiplex autism families confirm 15q11-q13 duplications as a cause of autism [abstract]. Am J Hum Genet 2004; 73 (Suppl): P975.

34 Keller K, Williams C, Wharton P et al: Routine cytogenetic and FISH studies for $17 \mathrm{p} 11 / 15 \mathrm{q} 11$ duplications and subtelomeric rearrangement studies in children with autism spectrum disorders. Am J Med Genet A 2003; 117: 105-111.

35 Bejjani BA, Saleki R, Ballif BC et al: Use of targeted array-based CGH for the clinical diagnosis of chromosomal imbalance: is less more? Am J Med Genet 2005; 134: 259-267.

36 Northrop EL, Ren H, Bruno DL et al: Detection of cryptic subtelomeric chromosome abnormalities and identification of anonymous chromatin using a quantitative multiplex ligationdependent probe amplification (MLPA) assay. Hum Mutat 2005; 26: $477-486$

37 Chen KS, Manian P, Koeuth T et al: Homologous recombination of a flanking repeat gene cluster is a mechanism for a common contiguous gene deletion syndrome. Nat Genet 1997; 17: $154-163$.

38 Shaw CJ, Bi W, Lupski JR: Genetic proof of unequal meiotic crossovers in reciprocal deletion and duplication of $17 \mathrm{p} 11.2 . \mathrm{Am} J$ Hum Genet 2002; 71: 1072-1081. 